Article

\title{
Coal-Electric Power Supply Chain Reduction and Operation Strategy under the Cap-and-Trade Model and Green Financial Background
}

\author{
Bowen Da ${ }^{1}$, Chuanzhe Liu ${ }^{1, *}$, Nana Liu ${ }^{1}$, Yufei Xia ${ }^{2}$ and Fangming Xie ${ }^{1}$ \\ 1 School of Management, China University of Mining and Technology, Xuzhou 221116, China; \\ helen.da@live.cn (B.D.); liunana1004@163.com (N.L.); m15246349728@163.com (F.X.) \\ 2 Business School, Jiangsu Normal University, Xuzhou 221116, China; 6020180093@jsnu.edu.cn \\ * Correspondence: rdean@cumt.edu.cn
}

Received: 13 March 2019; Accepted: 22 May 2019; Published: 28 May 2019

check for updates

\begin{abstract}
For reliving the pressure of air pollution and corresponding the sustainability development policy in China, the companies are urging the creation of a highly productive low-carbon supply chain. This work uses price regulation, the cap-and-trade model, and a green financial policy background to establish a strategy for the coal-electric power supply chain with two-level carbon reduction and operation with financial constraints. A Stackelberg model was built to help investigate the rate of thermal order realization, the carbon reduction strategy in the coal enterprise, and the amount of thermal energy ordered in the electric enterprise. Results show that under a green financial background, a high bank loan discount rate for investing in carbon reduction technology equates to large carbon reduction in coal enterprises, large quantities of thermal energy ordered in electric enterprises, and high profit for coal and electric enterprises. However, the realization rate of thermal power ordered decreased when the price regulation become strict, thereby reducing the profit and carbon emission in electric enterprise. Therefore, the thermal price regulation level increased, the profit on both company and the production did not respond with sensitivity, and the government could encourage a low carbon model by controlling the bank loan rate.
\end{abstract}

Keywords: coal-electric supply chain; double price regulation of coal-electric chain; green finance; carbon reduction

\section{Introduction}

The supply chain is a service commercial model which could achieve cooperation of development and inner system management. This study focuses on the coal-electric supply chain which is built for low carbon systems, meanwhile considering that two-side companies could have the optimal profits. Taking advantage of the supply chain model to study the supply-demand relationship, it may be widely spread in the practice, and the supply chain finance turns into a popular topic model around the world.

Combining the supply chain and the green finance due to the emergency environment pollution is positive, otherwise it would be harmful to the productivity of either one. In China, the electric enterprise exercises a monopoly of the electric market, and it has an obviously advantageous position in terms of market share. The character of our coal factory expanded rapidly and was explored in an extensive development model; consequently, the growth of economics breaks the balance of the environment. Therefore, the country began to control the energy industry's consumption due to the aggravation of the environment problem [1]. The statistics results have shown the growth of rural emissions from 2002, and in the same time, the quantity of carbon emissions in rural places increased about five times more than the quantity of carbon emissions in urban places in 2015. Since 
2008, different kinds of toxic gas such as sulfur, arsenic, fluorine, and mercury emissions rose sharply, caused by domestic coal burning. However, oppositely, the quantity of emissions from coal-fired power plants decreased [2]. From the above data, the environment problems due to the domestic coal burning in rural communities have been paid attention to, and the control on air pollution should have been put forward. Due to the harsh environment situation, the scholars attempted to solve environmental pollution, and the future research fields should focus on how to improve the technology of reducing carbon emission while preventing costs from increasing, in practice, environment-friendly ideas that are widely spread and accepted [3].

The amount of thermal power was kept at a high level and was enough, and the need for coal products decreased remarkably in the coal trade market. Consequently, the country also introduced clean energy, the resource of electric power mostly originated from "green" or "clean" energy, for example, wind power, nuclear power, and water power. The amount of carbon emission reduction from global electric power, including heat power, accounted for $40 \%$ of the total global percentage [4]. In our country, the electric power resource is restrained by the limitations of the Earth's power resource. Most of the electric power is transferred from coal products, the coal-electric power channel being one of the important supply chains in the electric power market, and thermal being the main electric power supplier. The portion accounts for more than $70 \%$, and the consumption of the coal products accounts for half of the total of the entire country's coal product consumption [5]. The expansion of the electric industry mainly depends on technology innovation and structural reformation. Exploration of novel green resources can increase the electric power generation efficiency continually, and carbon emission reduction via technology and reformation can produce ideal results [6]. Even the government encourages the clean energy to replace the fossil resource, but there exists some contradiction between developing the local economy and reconsidering the clean energy infrastructures after the 21st century in many places and the realms. Meanwhile, some people showed that the group prioritizes arranging the scale of technologies and infrastructure. Other people argue that the upgrade or renewable clean energy can satisfy this target: the named financial innovation and connection between financial and high technology [7].

In 2011, Beijing, Shanghai, Tianjin, Chongqing, Hubei, Guangdong, and Shenzhen began to build carbon emission right-traded markets, which were launched in 2014. At the end of 2017, the accumulated quantity of these seven trial cities exceeded 200 billion tons. The optimal operation strategies are switched when the above two policies are applied, and in the meantime, the variables influence each other [8]. Furthermore, the feed-in tariffs and investment in auxiliary equipment and agriculture intensification effectively expand the portion of renewable energy, and at the same time, it could reduce carbon emissions [9]. On the practical side, a Danish case study did not consider the characteristics of industry sectors other than thinking about the structure of industrial energy, its whole produce procedure, the part of energy consumption, and calculations for fossil fuel reduction [10].

This study uses the reverse induction of the Stackelberg model game theory, a productive leading model; it selects the coal enterprise as the starting point, builds two-stage equilibrium, and decides on the quantity and price of carbon reduction in China. This model hypothesis that, the manufacturer 1 decides their quantity of product, and manufacturer 2 makes their quantity decision after knowing manufacturer 1's decision. Therefore, when manufacturer 1 confirms their product quantity, it is better to acquaint them with manufacturer 2's decision. Then, we examine the way of reducing carbon emissions by considering the cap-and-trade model. At the last, a bank loan provides the money to support the spread of clean energy power. The rest of the paragraphs are arranged as below; Section 2 is literature review, Section 3 talks about the hypothesis and variables declaration. The mathematic data and analysis are located in Sections 4 and 5, and the last paragraph is the conclusion of this study.

\section{Literature Review}

This paper focuses on profit rearrangement in a decentralized strategy between coal and thermal power enterprise-integrated systems by relying on the Stackelberg model in the game theory in China. 
The study puts forward the green financial theory for encouraging the factories to reduce their carbon emission, and realize the sustainability development, hoping to use the coal-electric supply chain to achieve the optimal profit, and solve an optimal order quantity and price to get the balance of supply-side. Peng [11] said the coal companies with their retailers could achieve the balance of supply-side in the multi-target decision model and satisfy the profit goal. In the United Kingdom (UK), from survey results in 2008, over two-thirds of people prefer to purchase the products from the firms who take an active part in calling for carbon emission reduction [12]. In Babu's [13] study, the results identified that the "green" supply chain could keep stable and last quite a long time in a suitable equilibrium with various dimensions. So, it devotes to seek the factors which could influence the balance of equilibrium in a sustainability supply chain, and conclude the relationships between each other.

So far, the firms' carbon management systems play a key role in appealing to restrain the greenhouse gas emission. A carbon management system is described by Tang and Luo (2014) [14] as "a way to implement a firm's carbon strategy or policy to enhance the efficiency of input-use, mitigate emission and risks and avoid compliance costs or to gain a competitive advantage". A large body of literature is devoted to the research on carbon accounting in recent years $[15,16]$. However, less literature undertakes research on green chains using quantitative models on forward supply chains into environmental consideration. In China, the coal factory and the electric factory are all in the process of policy reformation and in the process of revolution, so a series of energy supply-and-demand problems have been put forward [17]. Furthermore, the relationship in coal and electric power enterprises directly affect the stability of demand and supply in the energy power market. Another paper considered the kind of channel which, under the cap-and-trade mechanism, in other words, the government distributed the total carbon emission rights into a decided portion, then through a specific way transits into the enterprises which created the carbon emissions during the production process, and the enterprises could buy or sell the carbon emission rights except for the decided portion by the government in the market. Besides, the cap-and-trade mechanism is suitable for the low-carbon supply chain, and no matter the manufacturer or the retailer, the joint emission reduction strategy is profitable [18].

In addition, the management model in a low-carbon quantitative supply chain could influence the result. The channel is based on the Stackelberg game theory and decentralized model. Using the Stackelberg game willingly leads to higher carbon emission reduction rates and lower retail price compared with the one using the Nash game [19]. For the decentralized model, the manufacturer and the retailer are responsible for their own profit, respectively, so they can be in charge of their own business. There are papers that have showed that a product's retail price and the government's carbon tax, using the decentralized decision-making mode, are higher than the one using the centralized decision-making mode. So, the paper pointed out that the centralized model is more beneficial to enterprises and governments than the decentralized model [20]. Under a particular carbon emission regulation, if the organization tries to find a way for the decentralized model to achieve the optimal social value as well as the centralized model, it may suggest that the government should set a more efficient and promising policy [21].

Even though the integrated regulations or policies have not been acquired yet, the energy services become diverse, but the scholars proved that the low-carbon awareness promote the channel members to invest in carbon emission reduction without any price regulation [22]. With the increase of peoples' awareness of carbon reduction, the enterprises will pay more attention to the green supply chain management (GSCM) model [23]. The extreme air pollution in China is mainly caused by the household low-quality coal consumption. In response, the government carried out a series of actions to push the high-quality coal consumption and the adoption of new-type coal stoves, and the new-type coal stoves significantly improve the quality of the coal production [24]. Imen Nouira [25] designed a forward supply chain which studies the impact of a carbon emissions-sensitive demand, and the results explored that the customers' carbon reduction awareness may influence the company's preference about the 
area of production and consumption. Luo [26] also found that the carbon traded price has a positive influence on the limit of carbon emission to retailer and producer, and in the centralized model, the quantity of carbon emissions were lower than the level in the decentralized model.

This study also considers finance for enlarged scales and new types of innovation to accomplish the amalgamation of finance and high technology. Especially for the period of defending the United State hegemony, the combination of finance and green technology may be a solution [27]. There are studies also trying to use financial ways to encourage people to widen the finance resource, for example, Aljazzar [28] says that adopting delays-in-payments enhances both environmental and economic performance in a low carbon supply chain with a cap-and-trade scheme through adjusting the parameters, including production rate, length of delay in payments, and so on, in profit equilibrium, the optimal ratio between decided variables could be solved and this flexibility makes the model easy to try in practice. On the contrary, Peng [29] proposed an advance payment with a risk compensation (APRC) mechanism where, in the process of trading, the distributor finances the payment and, correspondingly, the supplier provides a price discount. Then the result indicates that APRC is an effective way to compensate for funds shortage. Also, it is revealing that revenue sharing contracts can effectively benefit both the retailer and the manufacturer and promote the environment equality with lower carbon reduction. However, the retailer's revenue-sharing contract could make the effort to promote manufacturers abiding by the horizontal cooperation, and if the sharing ratio is fixed, the contract will bring higher profits for both sides [30]. There is another way the company always uses called the cost-sharing mechanism, and the result indicates that the channel members could coordinate against a cost-sharing contract inclusive of carbon emission reduction [31]. In Sun's [32] research, the contract also benefits the forest product channel to gain more profit. Despite the considered ways of finance for the group, the government introduces carbon tax through the governance tariffs to control the carbon emissions, but the performance of tax rate is worse than the subsidy rate [33]. However in China, because of the severe pollution conditions our people have lived in, the government decided to set up relative projects to reduce the emission pressure, taking the charge for the carbon emission into the resource tax, but as a single tax catalog. The research showed that when adopting the carbon tax would influence the result of carbon emission [34]. The minster of the developing and revolution department said the carbon tax may be put forward after 2020 in China.

This paper also designs the stock-out cost, and recently the companies have preferred to utilize the big data to implement a visual system for the supply chain of the thermal coal, therefore the power companies can choose the cost-effective material suppliers after comparing the price, simultaneously urging the power companies to reduce the storage cost as much as they can [35]. A strategic decision-making model considering the social cost on reducing carbon emissions and with the increase of the social cost, the quantity of carbon emission decreased, so the enterprise should burden the costs of carbon emissions for the low-carbon environment [36]. For reducing the stock-out cost, there is a study which thought of using price regulation. The research appeared to show that, under the double price regulation, the channel could not coordinate the manufacturer's order during the high season and the low season. However, the mutual subsidy mechanism could fulfill the quantity of seasonal products under the double price regulation [37].

Lastly, there are already study conclusions here, as the production quantities increased with the price of carbon emission right in the generally supply chain, and the ones that could be coordinated in wholesale price and cost sharing contracts [38]. It is different from the research before, as the subject of study is minimized by the type of industry that included the electric enterprise and the coal enterprise in the specific supply chain, and it assumed that the coefficient number of carbon emission costs in coal and electric enterprises were large enough. Due to the result in Zhou's [39] study, the increase of the unit product's carbon emission cost and the decrease of the system's carbon emission reduction, the carbon emission reduction should be decreased. 


\section{Description of the Equilibriums and Basic Hypotheses}

This article studies coal and electric enterprises; both are constrained strictly and should invest in a carbon emission reduction fee. In the cap-and-trade scheme and green financial environment, the operation system, reduction strategy, and green financial policy must be analyzed because they influence the coal-electric power supply chain. The main parameters and variables are as Table 1:

Table 1. Variable Declaration.

\begin{tabular}{|c|c|}
\hline $\begin{array}{l}s, m \text { : lower case, represent coal enterprise and electric } \\
\text { enterprise, respectively }\end{array}$ & $\begin{array}{l}e_{s 0}, e_{m 0}: \text { initial quantity of carbon emission in coal and } \\
\text { electric enterprises }\end{array}$ \\
\hline $\begin{array}{l}\pi_{s}, \pi_{m}: \text { represent coal enterprise and electric } \\
\text { enterprise, respectively }\end{array}$ & $\begin{array}{l}E_{g s}, E_{g m}: \text { limit of carbon emission to coal and electric } \\
\text { enterprises }\end{array}$ \\
\hline$p_{s 1}:$ price of coal product & $\begin{array}{l}c_{t s}, c_{t m}: \text { coefficient number of carbon emission cost in } \\
\text { coal and electric enterprises }\end{array}$ \\
\hline $\begin{array}{l}\alpha \text { : discount price of thermal power supplied to } \\
\text { electric enterprise }\end{array}$ & $r$ : rate of bank loan \\
\hline$p_{m}:$ price of electric power & $\begin{array}{l}\theta \text { : discount rate of bank loan for carbon emission } \\
\text { reduction }\end{array}$ \\
\hline$p_{t}:$ price of carbon emission right & $\begin{array}{l}k \text { : rate of thermal power transferred in coal enterprise, } \\
\text { decision variable }\end{array}$ \\
\hline$Q_{s}:$ quantity produced by coal enterprise & $\begin{array}{l}e_{s}: \text { quantity of carbon emission in coal enterprise, } \\
\text { decision variable }\end{array}$ \\
\hline$c_{s}, c_{m}:$ produced cost of coal and electric enterprises & $\begin{array}{l}Q_{m}: \text { quantity of thermal power ordered, decision } \\
\text { variable }\end{array}$ \\
\hline $\begin{array}{l}c_{w}: \text { coefficient number of thermal shortage cost in } \\
\text { coal enterprise }\end{array}$ & $\begin{array}{l}e_{m}: \text { quantity of carbon emission in electric enterprise, } \\
\text { decision variable }\end{array}$ \\
\hline$\lambda:$ quantity of electric power with one unit thermal & \\
\hline
\end{tabular}

This study has the following hypotheses.

Assumption 1. Electric power can be directly used or supplied.

Description of Assumption 1: The electric power produced by the electric enterprise can use electric net as an input, and the electric power can be used up and need not be stored.

Assumption 2. The coal-electric power supply chain is subject to price regulation.

First, the price of electric power, as related to people's well-being, can be regulated. Depending on this assumption, the price of electric power $p_{m}\left(p_{m}\right.$ represent for price of electric power) is a constant. Second, in the case of the wholesale price of thermal being higher than the retail price, the thermal price is $(1-\partial) p_{s 1}\left(p_{s 1}\right.$ represents the price of the coal product), and $(0<\partial<1)(\partial$ represents the discount price of thermal power supplied to the electric enterprise).

Assumption 3. The carbon emission reduction inputs of coal and electric enterprises are disposable.

When viewed as a quadratic function, they are $C_{s}\left(e_{s}\right)=\frac{1}{2} c_{t s} e_{s}{ }^{2}, C_{m}\left(e_{m}\right)=\frac{1}{2} c_{t m} e_{m}{ }^{2}$. $\left(c_{s}, c_{m}\right.$ represents the produced cost of coal and electric enterprises, $e_{s}, e_{m}$ represents the quantity of carbon emissions in coal or electric enterprise, $c_{t s}, c_{t m}$ represents the coefficient number of carbon emission costs in coal and electric enterprises).

It is difficult for enterprises to reduce the quantity of carbon emission; hence, $c_{t m}$ and $c_{t s}$ are infinitely large.

Assumption 4. Under the green financial background, an enterprise in the coal-electric power supply chain has a discount in interest rate when it invests in carbon emission reduction via technology.

The discount rate is $\theta(0<\theta<1)$ ( $\theta$ represents the discount rate of a bank loan for carbon emission reduction), the normal bank interest rate is $r(r$ represent for rate of bank loan), and the interest rate for investing in technology carbon emission reduction is $(1-\theta) r$. 
Assumption 5. Owing to the necessity of the coal-electric power supply chain, the coal enterprise needs to pay a shortage cost if the storage is insufficient.

The shortage cost is $c_{w}$ ( $c_{w}$ represent for coefficient number of thermal shortage cost in coal enterprise), and the shortage portion is $K=1-k$ ( $k$ represents the rate of thermal power transferred in coal enterprise, decision variable). If the shortage cost is a marginal increasing function related to shortage portion, $\frac{d C_{w}}{d k}>0, \frac{d^{2} C_{w}}{d k^{2}}>0$. The reason is that the larger the shortage portion is, the larger the shortage cost is. The shortage cost increases with the shortage portion, assuming that $C_{w}=c_{w}(1-k)^{2}$.

Based on this description and assumptions, this study examines the coal-electric power supply chain, which is shown in Figure 1, and it can be concluded into three lines to describe the cash flow movement.

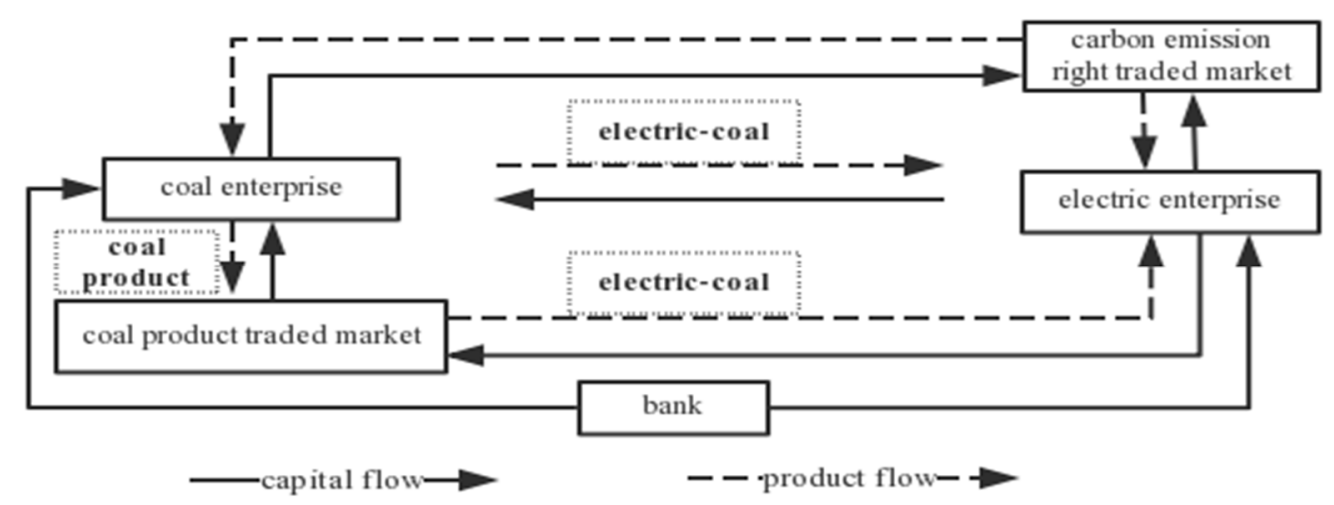

Figure 1. Capital and product flow system in coal-electric supply chain.

Figure 1 explains the capital and product flow working path, the double stage carbon reduction supply chain consists of one coal enterprise and one electric enterprise. The coal enterprise produces the coal product and electric coal for generating electric power, therein both the coal enterprise and the electric enterprise are both outputting carbon emission. However, the government institutes the limit of carbon emission, and also there is a carbon emission traded market to supply the extra emission right to be traded in regulated price. Reconsider the capital flow, price of coal product, and electric-coal hardly being decided by the market, the price of carbon emission rights also being regulated by the government, except the product profit and the emission right trading profit, the cost and the fee should be deducted. After realizing carbon emission reduction, the study proposes a green financial discount debt rate and divided the debt function into two parts, one for product resource and another one for emission reduction technology. For the purpose of obtaining optimal profits in the enterprise, whilst meanwhile being an environmentally friendly company, and accomplishing the task of sustainability development. The following variables were decided and negotiated: optimal coal emission reduction (em $\backslash \mathrm{es}$ ), carbon emission price, quantity of thermal power ordered, and bank credit rate, and trying to prove the quantity of carbon emission as playing a very important role in the coal-electric trade, and the influence in the above variables.

\section{Coal-Electric Power Supply Chain Reduction and Financing Strategy under the Cap-and-Trade Model}

In a decentralized decision, a Stackelberg model was built for coal and electric enterprises based on game theory, and the decision order is as follows: the electric enterprise orders thermal power from the coal enterprise, the coal enterprise decides on the rate of order realized, and both sides decide on the quantity of carbon reduction. This study applies backward induction and game theory to solve the functional problem. 


\subsection{Optimal Strategy of the Coal Enterprise under Financial Constraints and Cap-and-Trade Model}

Depending on the components of profit, the profit formula of the coal enterprise could be derived as below:

$$
\begin{aligned}
\pi_{s}= & p_{s 1}\left(Q_{s}-k Q_{m}\right)+(1-\alpha) p_{s 1} k Q_{m}-(1+r) c_{s} Q_{s}-p_{t}\left[\left(e_{s 0}-e_{s}\right) Q_{s}-E_{g s}\right] \\
& -\frac{1}{2}[1+(1-\theta) r] c_{t s} e_{s}^{2}-c_{w}(1-k)^{2}
\end{aligned}
$$

$Q_{m}$ is the quantity ordered from the electric enterprise, the rate of thermal power transferred in the coal enterprise is $k$, the coal enterprise supplies $k Q_{m}$ ton of thermal power as $(1-\alpha) p_{s 1} \times 10,000$ dollars to the electric enterprise, and the rest of coal $Q_{s}-k Q_{m}$ is sold as $p_{s 1}$ in the commodity coal market. Under the cap-and-trade model, the quantity of carbon emission limit that is allocated to the coal enterprise is $E_{g s}$. The coal enterprise can buy or sell it at market price $p_{t}$ when the quantity of carbon emission is higher than the limited quantity. The quantity of carbon emission that is higher than the limit is $\left(e_{s 0}-e_{s}\right) Q_{s}-E_{g s}$. If the initial fund in the coal enterprise is 0 and the bank loan rate for production capital is $r$, under the green financial policy, the bank loan rate for carbon reduction investment is $(1-\theta) r$.

The coal enterprise decides on the rate of thermal transfer and quantity of carbon reduction to maximize its profit, and the optimal decision satisfies Proposition 1.

Proposition 1. The optimal rate of thermal transfer in the coal enterprise is $k^{*}$, and the optimal quantity of carbon emission in the coal enterprise is $e_{s}^{*}$.

$$
\left\{\begin{array}{l}
k^{*}=1-\frac{\alpha Q_{m} p_{s 1}}{2 c_{w}} \\
e_{s}^{*}=\frac{p_{t} Q_{s}}{[1+(1-\theta) r] c_{t s}}
\end{array}\right.
$$

(Proof of Proposition 1 is in Appendix A.1).

\subsection{Optimal Strategy of the Electric Enterprise under Financial Constraints and Cap-and-Trade Model}

Alternatively, the manufacturer is the electric enterprise in the supply chain, and the profit could be described as below:

$$
\begin{aligned}
& \pi_{m}=\left(p_{m}-c_{m}\right) \lambda Q_{m}-(1+r)\left[(1-\alpha) p_{s 1} k+p_{s 1}(1-k)\right] Q_{m} \\
& -p_{t}\left[\left(e_{m 0}-e_{m}\right) Q_{m}-E_{g m}\right]-\frac{1}{2}[1+(1-\theta) r] c_{t m} e_{m}{ }^{2}
\end{aligned}
$$

The quantity of thermal power ordered is $Q_{m}$, and the rate of thermal transfer in the coal enterprise is $k$. Thus, the electric enterprise buys $k Q_{m}$ ton of thermal power at a regulated price $(1-\alpha) p_{s 1}$, and the rest of the $(1-k) Q_{m}$ ton of thermal power is sold in the commodity market at price $p_{s 1}$. Under the cap-and-trade model, the limit quantity of carbon emission that is allocated to the electric enterprise is $E_{g m}$. If the quantity of carbon emission in $\left(e_{m 0}-e_{m}\right) Q_{m}-E_{g m}$ is higher or lower than the limit quantity of carbon emission, then the electric enterprise can buy or sell the right of carbon emission at price $p_{t}$. Like the coal enterprise, if the initial fund in the electric enterprise is 0 and the bank loan rate for production capital is $r$, under the green financial policy, the bank loan rate for carbon reduction investment is $(1-\theta) r$.

Based on backward induction, the electric enterprise decides on the quantity of thermal power ordered and the quantity of carbon emission reduction in consideration of the rate of the thermal transfer function in the coal enterprise and aiming to maximize the profit of the enterprise. Hence, the optimal decision model is:

$$
\max _{Q_{m}, e_{m}} \pi_{m} \quad \text { s.t. }
$$


Proposition 2. The optimal quantity of thermal power ordered $Q_{m}{ }^{*}$ and the optimal quantity of carbon emission $e_{m}{ }^{*}$ in the electric enterprise are:

$$
\left\{\begin{array}{l}
Q_{m}{ }^{*}=\frac{[1+(1-\theta) r] c_{w} c_{t m}\left[\lambda p_{m}-\lambda c_{m}-(1+r)(1-\alpha) p_{s 1}-p_{t} e_{m 0}\right]}{{ }^{*}(1+r)[1+(1-\theta) r] c_{t m} \alpha^{2} p_{s 1}{ }^{2}-c_{w w} p_{t}{ }^{2}} \\
e_{m}{ }^{*}=\frac{p_{t} Q_{m}{ }^{*}}{[1+(1-\theta) r] c_{t m}}
\end{array}\right.
$$

(Proof of Proposition 2 is in Appendix A.2).

The optimal quantity of thermal power ordered and the optimal quantity of carbon emission could be obtained, as it indicated that the electric enterprise could through adjusting the variables to achieve the best situation in the end.

\section{Discussion and Mathematical Examination}

This section discusses the system of the cap-and-trade model and the effect mechanism of green financial policy. To prove the results of the study, this paper applies a mathematical examination. From the research data, the relevant parameters are set as follows: $c_{s}=300$ dollar/ton, $\alpha=0.3$, $\lambda=0.3(\mathrm{~kW} / \mathrm{h} / \mathrm{ton}), p_{s 1}=700 \mathrm{dollar} / \mathrm{ton}, Q_{s}=500,000$ thousands $/$ ton, $E_{g s}=70$ thousands $/$ ton, $E_{g m}=15$ thousands $/$ ton, $p_{t}=60$ dollar $/$ ton, $e_{s 0}=2$ ton $/$ ton, $e_{m 0}=2.5$ ton $/$ ton, $c_{m}=800$ dollar $/ \mathrm{kW} / \mathrm{h}$, $p_{m}=3900$ dollar $/ \mathrm{kW} / \mathrm{h}, c_{t m}=2000, c_{t s}=2000, r=0.06, \theta=0.2$ and $c_{w}=3000$.

\subsection{Influence of Carbon Emission Reduction Cost}

Proposition 3. $\frac{d Q_{m}}{d c_{t m}}<0, \frac{d e_{m}^{*}}{d c_{t m}}<0$, and $\frac{d k^{*}}{d c_{t m}}>0$.

(Proof of Proposition 3 is in Appendix A.3).

Proposition 3 means that the larger the coefficient number of carbon emission cost in the electric enterprise is, the harder it is to reduce the quantity of carbon emission and the lower the quantities of carbon reduction and thermal ordered are. At the same time, because the quantity of thermal power ordered is decreased, the coal enterprise increases the rate of thermal transfer. Proposition 3 is implied in management experience through the subsidy of the carbon reduction cost by easing the burden of the carbon reduction cost in enterprises, and by encouraging an enterprise to level up its degree of reducing the quantity of carbon emission. These will increase the productiveness of the electric enterprise.

Then, from Equation (2), knowing that $e_{s}^{*}=\frac{p_{t} Q_{s}}{[1+(1-\theta) r] c_{t_{s}}}$, the following proposition can be concluded.

Proposition 4. $\frac{d e_{s}^{*}}{d c_{t s}}<0$.

Proposition 4 shows that the larger the coefficient number of carbon emission cost in the coal enterprise is, the harder it is to reduce the quantity of carbon emission. The quantity of carbon reduction decreases relatively. In practice, by considering Proposition 4, the government could rely on the measurement of carbon reduction subsidy, ease the burden of the carbon reduction cost in enterprises, and encourage enterprises to level up their degree of reducing carbon emission.

Figures 2 and 3, which represent the influence of the cost of carbon reduction and profit of the electric, as well as the coal enterprise, the data all come from practical life in a private electric energy power company in Xuzhou, Jiangsu, China and a similar scale coal company's financial report. It is obvious that both electric enterprises and coal enterprises all appeared in the downward trend, therefore the two figures imply the following: the larger the coefficient number of carbon emission cost in coal and electric enterprises is, the harder it is to reduce carbon emission and the lower the profit is in coal and electric enterprises. 


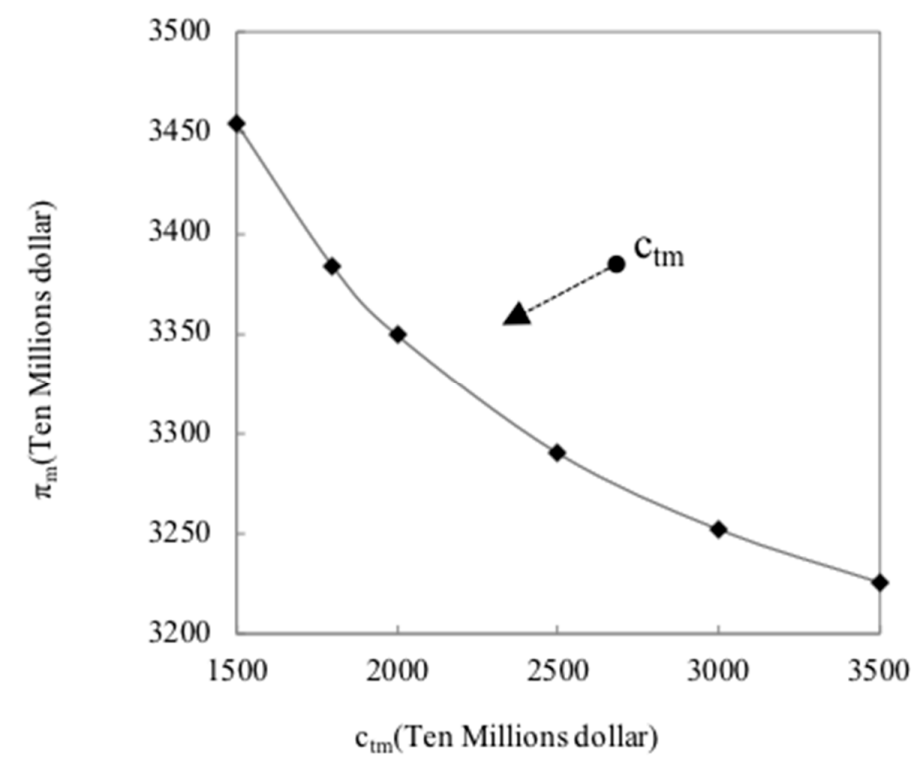

Figure 2. Influence of the cost of carbon reduction and profit of the electric enterprise.

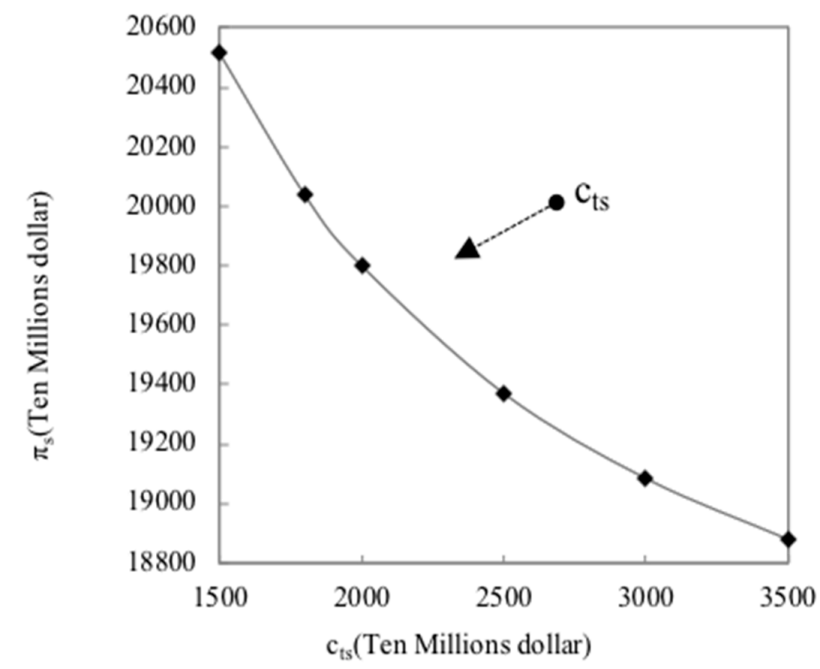

Figure 3. Influence of the cost of carbon reduction and profit of the coal enterprise.

5.2. Influence of Bank Loan Rate and Discount in Bank Loan Rate for Green Finance

Proposition 5. $\frac{d e_{m}^{*}}{d r}<0, \frac{d e_{s}^{*}}{d r}<0, \frac{d Q_{m}^{*}}{d r}<0, \frac{d k^{*}}{d r}>0$.

(Proof of Proposition 5 is in Appendix A.4).

Proposition 5 shows that the higher the bank loan rate is, the lower carbon reduction is in coal and electric enterprises. In other words, increasing the cost of finance will not help increase the investment in carbon reduction. As the bank loan rate increases, the productiveness of the electric enterprise is restrained. The rate of thermal transfer increases because of the decrease in the quantity of thermal ordered in the coal enterprise.

Proposition 6. $\frac{d e_{m}^{*}}{d \theta}>0, \frac{d e_{s}^{*}}{d \theta}>0, \frac{d Q_{m}^{*}}{d \theta}>0$

(Proof of Proposition 6 is in Appendix A.5).

Proposition 6 illustrates that in the background of green finance, with the increase in the discount rate of bank loans for carbon emission reduction, the quantity of carbon reduction in the coal enterprise, 
the quantity of carbon reduction in the electric enterprise, and the quantity of thermal power ordered in the electric enterprise are all increasing. In practice, Proposition 6 could be applied in the process of operation activity. So, it suggests that coal and electric enterprises should increase the quantity of carbon reduction and improve the productiveness of the electric enterprise.

Figures 4 and 5 illustrate that under a green financial environment, the discount rate of bank loans for carbon emission reduction affects the profit of the enterprise. The discount rate of bank loans for carbon emission reduction increases, which in turn increases the profit of the enterprise. In conclusion, green financing is beneficial for increasing enterprise profits.

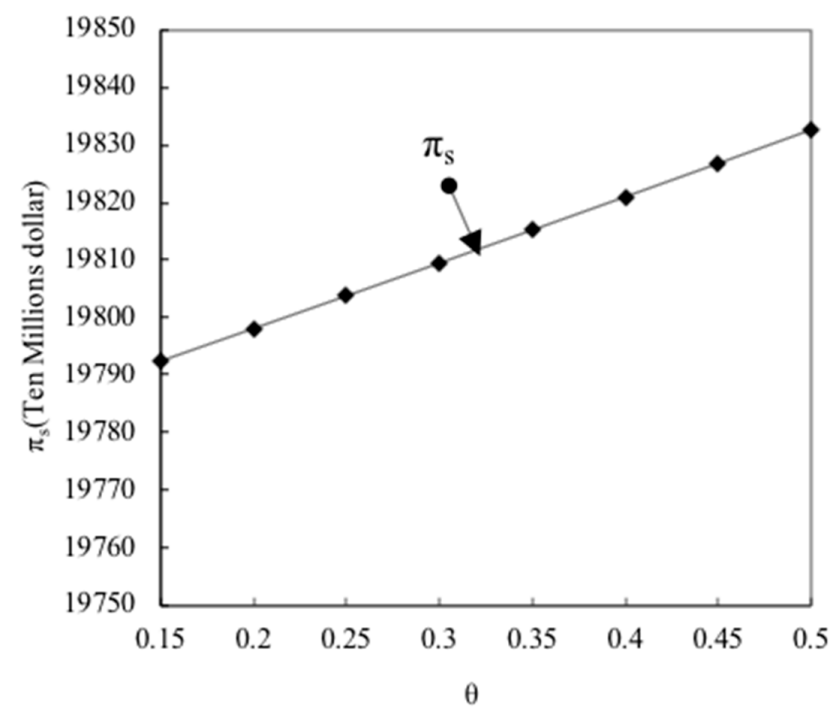

Figure 4. Influence of the discount rate of bank loan for carbon reduction and profits in coal enterprise.

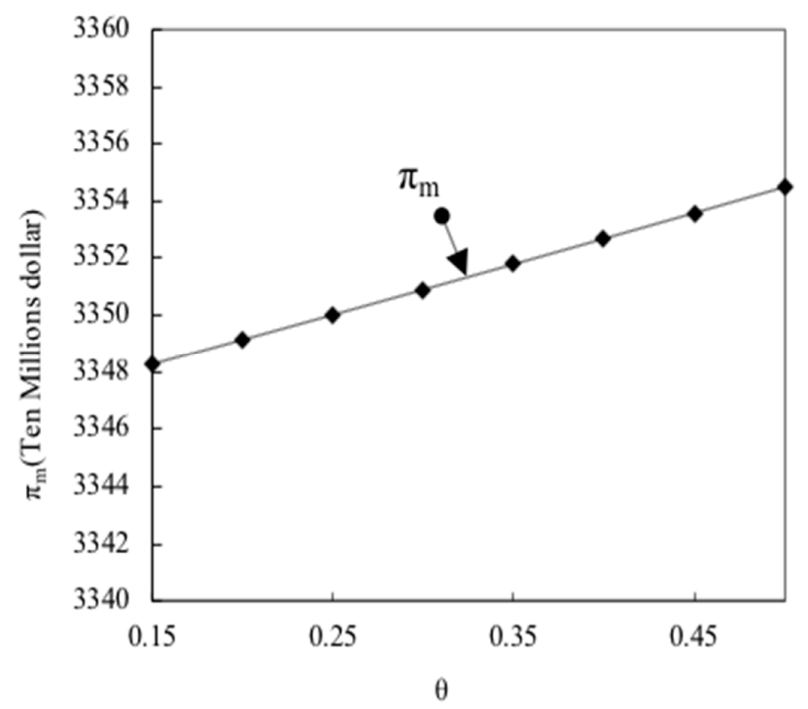

Figure 5. Influence of the discount rate of bank loans for carbon reduction and profit in the electric enterprise.

\subsection{Influence of Price Regulation Policy}

Proposition 7. $\frac{d e_{m}^{*}}{d p_{m}}>0, \frac{d Q_{m}{ }^{*}}{d p_{m}}>0, \frac{d k^{*}}{d p_{m}}<0$.

(Proof of Proposition 7 is in Appendix A.6). 
Proposition 7 shows that with the increase in electric price, the productivity and the enthusiasm for carbon reduction increase. The result means that the current price regulation policy is not beneficial for investing in carbon reduction in the electric enterprise and enhancing the enthusiasm for carbon reduction. The government should explore a way to build a fairy open market to present the electric price, and by setting the peak price and valley price in the measurement, and also introducing the dynamic trading scheme. Therefore, it may benefit for improving productivity and enthusiasm for reducing carbon emission in the electric enterprise.

\subsection{Influence of the Price of Carbon Emission Right}

This paper hoped to find a way to control the carbon emission, and the carbon emission indicates that you can trade the extra carbon emission right in the carbon market, and the equilibrium concludes the traded price. This paper assumed that the price affected the quantity of carbon emission.

Figures 6-8 show the results of conducting thermal price regulation, the effect on the profit of both enterprises in the coal-electric power supply chain, the quantity of carbon emission reduction, and the quantity of thermal power ordered. According to Figure 6, an interesting result is obtained when increasing the degree of price regulation level. The lower the price of thermal power is, the lower the profit of the electric enterprise is. If the decreasing trend is maintained, then the profit of the coal enterprise may increase. This result is because the stricter the thermal price regulation is, the lower the rate of realizing the thermal order is. The electric enterprise has to buy coal products from the coal market at the current price. Therefore, the profit of the electric enterprise could decrease. However, the coal enterprise would prefer to sell the coal product in the market, thereby increasing the profit of the coal enterprise. Figures 7 and 8 show the result of thermal price regulation, the price regulation of thermal power becomes strict, and the quantities of thermal power ordered in the electric enterprise and carbon emission show a downward trend. In conclusion, there are some management tips that can be obtained from Figures 6-8. The price regulation scheme decreases the realization rate of thermal power ordered and causes an electric power-coal supply contradiction, thereby reducing the electric enterprise profit, depressing the positive attitude toward producing the product, and reducing the quantity of carbon emission in the electric enterprise. The result does not meet the expectation. The governor should consider applying a scheme that keeps the coal price correlated with the electric price and then make electric and coal prices open to the market to relieve the stress on the supply of coal and electric power and solve the contradiction between coal and electric enterprises.

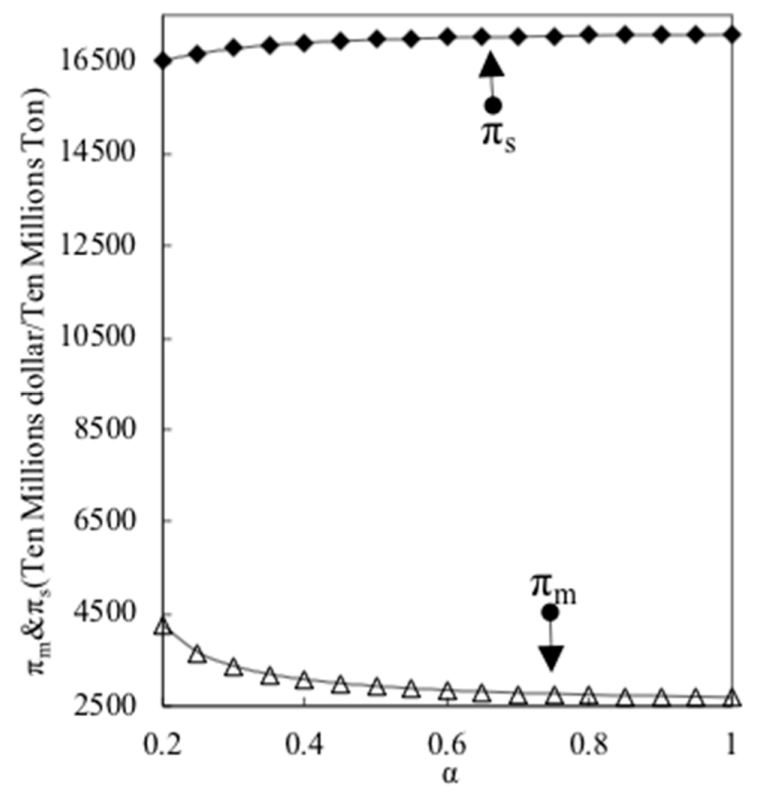

Figure 6. Influence of price regulation in thermal and enterprise profits. 


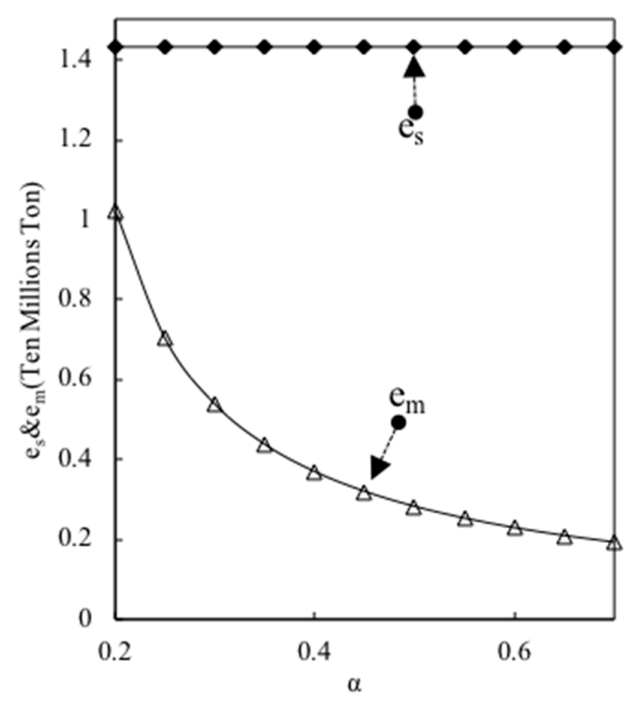

Figure 7. Influence of thermal price regulation and carbon quantity reduction.

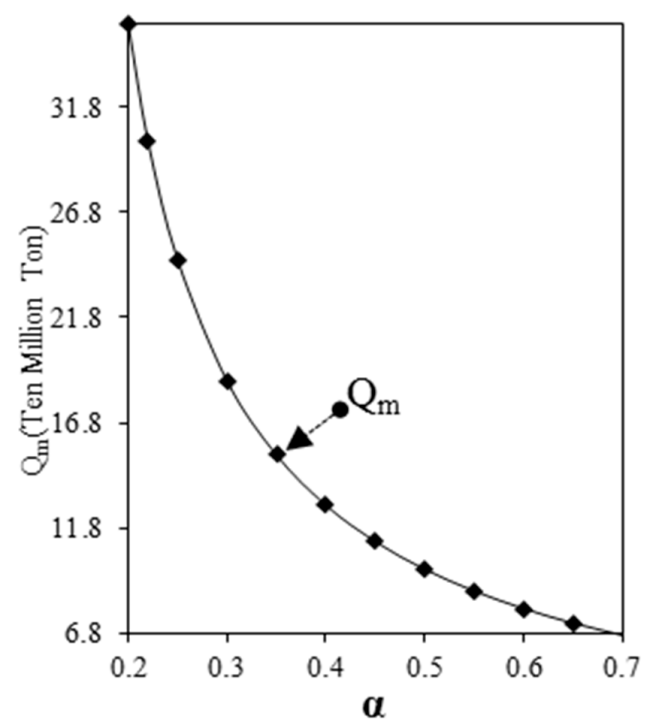

Figure 8. Influence of the discount price of thermal and quantity of thermal ordered.

Figure 9 shows the influence of carbon emission price on the quantity of carbon emission reduction in the coal-electric power supply chain. With increasing carbon emission prices, the quantities of carbon emission reduction in coal and electric enterprises increase. The result means that if the carbon emission reduction price could be kept in an appropriate value, it will encourage investment on reducing carbon emission in the coal enterprise. 


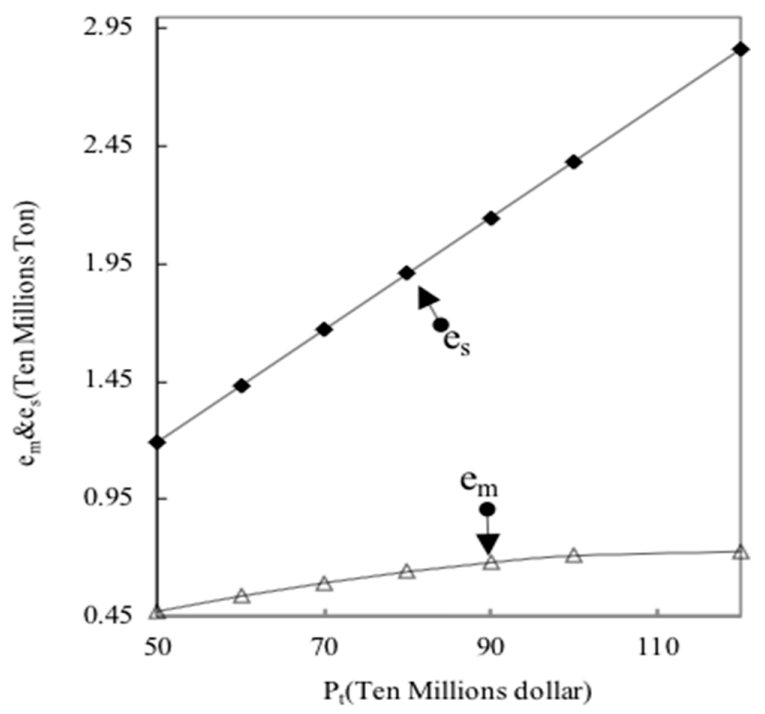

Figure 9. Influence of the price of carbon emission right and quantity of carbon reduction.

\section{Conclusions}

This study builds a coal-electric power supply chain model that depends on two-level price regulation and both of them conduct to reduce the carbon emission. It assumed that the carbon emission limit governed by the government, deducting the amount of limitation, the rest of carbon emission portion could be traded in the carbon trading market. Meanwhile, this working hypothesis that the financial support could come from commercial banks, under the green financial background, financial support can be divided into two parts: one for product material and another one for financing the cost of carbon emission reduction. The bank rate for supporting product material is normal, but the bank rate for financing the cost of carbon emission reduction entails a discount. For example, the company takes advantage of the high technology to increase the burning efficiency, and in that way, the need for coal products and thermal decreased in the same time, as did the carbon emissions. The green finance could appeal to more manufactures to choose an environmentally friendly production model, from the analysis results, the average bank loan rate is around $6 \%$, and the lower bank rate makes the manufacturers and retailers prefer the green production mode. Actually, the low carbon emission is basically rooted in the upgrade of traditional resources or replaced by the newly green power resources. In this paper, it is assumed that the electric power generated by the coal plant, the way to relive the carbon emission pressure, mostly depends on the new technology improving the efficiency of transit rates, making the coal completely for burning. Also, increasing the utilization of coal product could decrease the coal product quantity in the same level. The technology could not only cut down the coal consumption, but also be good for the company's profits in the long run. In reality, high technology promotes green development and realizes the sustainability development, sufficiently decreases the carbon emissions, and benefits the environment. No matter what kind of path the company chooses, through financing, the way to solve the money shortage could better achieve the aim of carbon reduction.

Besides the assumptions and content description above, the results could be modified so that the cost of carbon emission reduction, bank loan rates, the discount of bank loan rates under green financial backgrounds, price regulation policy, and carbon emission price are all influenced by the following variables: quantity of thermal power ordered, quantity of carbon emission reduction, and transferred rate of thermal power. In other words, to improve enterprises' profits, the managers or shareholders should pay more attention to the above variables. Also, the subject of building the green low-carbon supply chain is encouraging enterprises to update the power resource structure and protecting the environment. In practical situations, the company could lower the cost of carbon reduction, such as using the clean coal product or higher burning efficiency thermal; the bank increases the loan 
discount rate under the green financial background to encourage enterprises to reduce carbon emission. Regarding the study about the coal-electric power supply chain based on China, perhaps the current electric price regulation is unsuitable for promoting carbon reduction and improving the enthusiasm for production. Furthermore, as the thermal price becomes stricter, the current average data is about $50 \%$, and the realization rate for thermal power ordered becomes lower. From the result, it could be suggested that, in the future, the government or relative departments could consider building a price correspondence market which includes coal and electric enterprises, all the parties should publish their information in the open market, and the price and other information are dynamic. By introducing the price response scheme, the contradiction problem in the coal-electric power chain may be partly relieved. Simultaneously, the overcapacity problem in China could also be relived. Therefore, it could lead to thermal industry growth in health and balance.

Last but not least, this study could be explored; the whole chapters have mainly discussed the coal-electric power supply chain, so the study object is limited. The paper's aim is to protect the environment and encourage the environment-friendly enterprises development. Except for the content of study, the financing solution all count on bank loans, and in the next study, more flexible financing solutions for enterprises should be considered.

Author Contributions: Conceptualization, B.D.; Data curation, B.D., N.L. and F.X.; Formal analysis, B.D. and C.L.; Funding acquisition, C.L.; Investigation, B.D., C.L., N.L. and Y.X.; Methodology, B.D. and Y.X.; Resources, F.X.; Software, B.D. and N.L.; Supervision, C.L.; Writing—original draft, B.D.; Writing—review and editing, Y.X. and F.X.

Funding: This research was funded by the "Double-First Class" Think Tank Program of China University of Mining and Technology (Grant No. 2018WHCC01).

Acknowledgments: The authors are grateful for the financial support provided by the "Double-First Class". Think Tank Program of China University of Mining and Technology (No.2018WHCC01).

Conflicts of Interest: The authors declare no conflict of interest. The funders had no role in the design of the study; collection, analyses, or interpretation of data, writing of the manuscript, and decision to publish the results.

\section{Appendix A.}

Appendix A.1. Proof of Proposition 1

As Equation (1) shows, $\frac{d \pi_{s}}{d k}=(1-k) 2 c_{w}-\alpha Q_{m} p_{s 1}, \frac{d \pi_{s}}{d e_{s}}=p_{t} Q_{s}-[1+(1-\theta) r] c_{t s} e_{s}, \frac{d^{2} \pi_{s}}{d k^{2}}=-2 c_{w}<0$, $\frac{d^{2} \pi_{s}}{d e_{s}^{2}}=-[1+(1-\theta) r] c_{t s}<0, \frac{d^{2} \pi_{s}}{d e_{s} d k}=0$.

Thus, it can be concluded as a Hessian matrix.

$$
H=\left[\begin{array}{cc}
-2 c_{w} & 0 \\
0 & -[1+(1-\theta) r] c_{t s}
\end{array}\right]
$$

However, $\operatorname{det}\left(H_{11}\right)=-2 c_{w}<0, \operatorname{det}(H)=2[1+(1-\theta) r] c_{w} c_{t s}>0$, such that the Hessian matrix is negative. The optimal rate of thermal transfer $k^{*}$ and the optimal quantity of carbon emission $e_{s}^{*}$ exist. Supposing that $\frac{d \pi_{s}}{d k}=0$ and $\frac{d \pi_{s}}{d e_{s}}=0$, from the above, the optimal $k^{*}$ and $e_{s}^{*}$ can be obtained in Equation (2).

\section{Appendix A.2. Proof of Proposition 2}

As Equation (4) shows:

$$
\begin{gathered}
\frac{d \pi_{m}}{d Q_{m}}=\frac{\partial \pi_{m}}{\partial Q_{m}}+\frac{\partial \pi_{m}}{\partial k^{*}} \frac{\partial k^{*}}{\partial Q_{m}} \\
=\lambda\left(p_{m}-c_{m}\right)-\frac{(1+r) Q_{m} \alpha^{2} p_{s 1^{2}}}{c_{w}}-(1+r)(1-\alpha) p_{s 1}-p_{t}\left(e_{m 0}-e_{m}\right) \\
\frac{d \pi_{m}}{d e_{m}}=p_{t} Q_{m}-[1+(1-\theta) r] c_{t m} e_{m}
\end{gathered}
$$


So, $\frac{d^{2} \pi_{m}}{d Q_{m}{ }^{2}}=-(1+r) \frac{\alpha^{2} p_{s 1}^{2} Q_{m}}{2 c_{w}}<0, \frac{d^{2} \pi_{m}}{d e_{m}^{2}}=-[1+(1-\theta) r] c_{t m}<0, \frac{d^{2} \pi_{m}}{d e_{m} d Q_{m}}=p_{t}>0$. It can be solved by the Hessian matrix

$$
H=\left[\begin{array}{cc}
-(1+r) \frac{\alpha^{2} p_{s 1}{ }^{2} Q_{m}}{2 c_{w}} & p_{t} \\
p_{t} & -[1+(1-\theta) r] c_{t m}
\end{array}\right]
$$

As shown by Assumption $3, c_{t m}$ is infinitely large. It can be solved as $\operatorname{det}\left(H_{11}\right)=-(1+r) \frac{\alpha^{2} p_{s 1}{ }^{2} Q_{m}}{2 c_{w}}<$ $0, \operatorname{det}(H)=\frac{(1+r)[1+(1-\theta) r] c_{t m} \alpha^{2} p_{s 1}^{2} Q_{m}}{2 c_{w}}-p_{t}^{2}>0$.

The above Hessian matrix is negative, and the optimal quantity of thermal power ordered $Q_{m}{ }^{*}$ and the optimal quantity of carbon emission $e_{m}{ }^{*}$ in the electric enterprise exist. If $\frac{d \pi_{m}}{d Q_{m}}=0$ and $\frac{d \pi_{m}}{d e_{m}}=0$, they can be solved as Equation (5).

Appendix A.3. Proof of Proposition 3

From Equation (5), it may have

$$
Q_{m}{ }^{*}=\frac{[1+(1-\theta) r] c_{w}\left[\lambda p_{m}-\lambda c_{m}-(1+r)(1-\alpha) p_{s 1}-p_{t} e_{m 0}\right]}{(1+r)[1+(1-\theta) r] \alpha^{2} p_{s 1}^{2}-c_{w} p_{t}^{2} / c_{t m}}
$$

Thus, $\frac{d Q_{m}{ }^{*}}{d c_{t m}}<0$. Given that $\frac{d e_{m}{ }^{*}}{d Q_{m}{ }^{*}}=\frac{p_{t}}{[1+(1-\theta) r] c_{t m}}>0$, it may have

$$
\frac{d e_{m}{ }^{*}}{d c_{t m}}=\frac{d e_{m}^{*}}{d Q_{m}{ }^{*}} \cdot \frac{d Q_{m}^{*}}{d c_{t m}}<0
$$

From Equation (2), it can be obtained $k^{*}=1-\frac{\alpha p_{s 1} Q_{m}{ }^{*}}{2 c_{w}}, \frac{d k^{*}}{d Q_{m}{ }^{*}}<0$. Therefore,

$$
\frac{d k^{*}}{d c_{t m}}=\frac{d k^{*}}{d Q_{m}^{*}} \cdot \frac{d Q_{m}^{*}}{d c_{t m}}>0
$$

Appendix A.4. Proof of Proposition 5

From Equation (2), the result showed that $e_{s}{ }^{*}=\frac{p_{t} Q_{s}}{[1+(1-\theta) r] c_{t s}}$. Then it can be obtained $\frac{d e_{s}{ }^{*}}{d r}<0$. Then, from Equation (5), the conclusion as following:

$$
Q_{m}{ }^{*}=\frac{c_{w} c_{t m}\left[\left(\lambda p_{m}-\lambda c_{m}-p_{t} e_{m 0}\right) /(1+r)-(1-\alpha) p_{s 1}\right]}{c_{t m} \alpha^{2}-c_{w} p_{t}^{2} /[(1+r)[1+(1-\theta) r]]}
$$

The conclusion can be easily obtained $\frac{d Q_{m}{ }^{*}}{d r}<0$. From $e_{m}{ }^{*}=\frac{p_{t} Q_{m}{ }^{*}}{[1+(1-\theta) r] c_{t m}}$, it can derive $\frac{d e_{m}{ }^{*}}{d r}<0$. Given that $k^{*}=1-\frac{\alpha p_{s 1} Q_{m}}{2 c_{w}}$ and $\frac{d k^{*}}{d r}=\frac{d k^{*}}{d Q_{m}{ }^{*}} \cdot \frac{d Q_{m}{ }^{*}}{d r}$, it could infer that $\frac{d k^{*}}{d r}>0$.

Appendix A.5. Proof of Proposition 6

From Equation (2), it was known that $e_{s}^{*}=\frac{p_{t} Q_{s}}{[1+(1-\theta) r] c_{t s}}$. The result is $\frac{d e_{s}^{*}}{d \theta}>0$. From Equation (5), it could have:

$$
Q_{m}{ }^{*}=\frac{c_{w} c_{t m}\left[\lambda p_{m}-\lambda c_{m}-(1+r)(1-\alpha) p_{s 1}-p_{t} e_{m 0}\right]}{(1+r) c_{t m} \alpha^{2}-c_{w} p_{t}^{2} /[1+(1-\theta) r]}
$$

Hence, it could have $\frac{d Q_{m}{ }^{*}}{d \theta}>0$ and $e_{m}{ }^{*}=\frac{p_{t} Q_{m}{ }^{*}}{[1+(1-\theta) r] c_{t m}}$. The conclusion could be derived $\frac{d e_{m}{ }^{*}}{d \theta}>0$. Appendix A.6. Proof of Proposition 7

From Equation (5), it can be shown as below:

$$
Q_{m}{ }^{*}=\frac{[1+(1-\theta) r] c_{w} c_{t m}\left[\lambda p_{m}-\lambda c_{m}-(1+r)(1-\alpha) p_{s 1}-p_{t} e_{m 0}\right]}{(1+r)[1+(1-\theta) r] c_{t m} \alpha^{2}-c_{w} p_{t}^{2}}
$$


Apparently, $\frac{d Q_{m}{ }^{*}}{d p_{m}}>0$, and because $\frac{d e_{m}{ }^{*}}{d Q_{m}{ }^{*}}=\frac{p_{t}}{[1+(1-\theta) r] c_{t m}}>0$, the equations could be derived as: $\frac{d e_{m}{ }^{*}}{d p_{m}}=\frac{d e_{m}{ }^{*}}{d Q_{m}{ }^{*}} \cdot \frac{d Q_{m}{ }^{*}}{d p_{m}}>0$.

From Equation (2), $k^{*}=1-\frac{Q_{m}{ }^{*} p_{11} \alpha}{2 c_{w}}, \frac{d k^{*}}{d Q_{m}^{*}}<0$; therefore,

$$
\frac{d k^{*}}{d p_{m}}=\frac{d k^{*}}{d Q_{m}^{*}} \cdot \frac{d Q_{m}^{*}}{d p_{m}}<0
$$

\section{References}

1. Lam, P. Energy in China: Development and prospects. China Perspect. 2005, 59, 14-25.

2. Zhao, C.; Luo, K. Household consumption of coal and related sulfur, arsenic, fluorine and mercury emissions in China. Energy Policy 2018, 112, 221-232. [CrossRef]

3. Leonzio, G. An innovative trigeneration system using biogas as renewable energy. Chin. J. Chem. Eng. 2018, 26, 1179-1191. [CrossRef]

4. Bilgen, S.; SarıKaya, I. Contribution on Turkey's electricity production development of primary green energy resources. Energy Sources Part B Econ. Plan. Policy 2017, 12, 876-882. [CrossRef]

5. Ghaffour, N.; Bundschuh, J.; Mahmoudi, H.; Goosen, M.F.A. Renewable energy-driven desalination technologies: A comprehensive review on challenges and potential applications of integrated systems. Desalination 2015, 356, 94-114. [CrossRef]

6. Sovacool, B.K.; Lipson, M.M.; Chard, R. Temporality, vulnerability, and energy justice in household low carbon innovations. Energy Policy 2019, 128, 495-504. [CrossRef]

7. Jans, L.; Bouman, T.; Fielding, K. A Part of the Energy "In Crowd": Changing People's Energy Behavior via Group-Based Approaches. IEEE Power Energy Mag. 2018, 16, 35-41. [CrossRef]

8. Yu, S.W.; Zheng, S.H.; Li, X.; Li, L.X. China can peak its energy-related carbon emissions before 2025: Evidence from industry restructuring. Energy Econ. 2018, 73, 91-107. [CrossRef]

9. Bieber, N.; Ker, J.H.; Wang, X.; Triantafyllidis, C.; van Dam, K.H.; Koppelaar, R.H.; Shah, N. Sustainable planning of the energy-water-food nexus using decision making tools. Energy Policy 2018, 113, 584-607. [CrossRef]

10. Wiese, F.; Baldini, M. Conceptual model of the industry sector in an energy system model: A case study for Denmark. J. Clean. Prod. 2018, 203, 427-443. [CrossRef]

11. Peng, H.J.; Pang, T.; Cong, J. Coordination contracts for a supply chain with yield uncertainty and low-carbon preference. J. Clean. Prod. 2018, 205, 291-302. [CrossRef]

12. Ang, B.W.; Choong, W.L.; Ng, T.S. Energy security: Definitions, dimensions and indexes. Renew. Sustain. Energy Rev. 2015, 42, 1077-1093. [CrossRef]

13. Babu, S.; Mohan, U. An integrated approach to evaluating sustainability in supply chains using evolutionary game theory. Comput. Oper. Res. 2018, 89, 269-283. [CrossRef]

14. Tang, Q.; Luo, L. Carbon management systems and carbon mitigation. Aust. Account. Rev. 2014, 24, 84-98. [CrossRef]

15. Luo, L.; Lan, Y.C.; Tang, Q. Corporate incentives to disclose carbon information: Evidence from the CDP Global 500 report. J. Int. Financ. Manag. Account. 2012, 23, 93-120. [CrossRef]

16. Luo, L.; Tang, Q.; Lan, Y.C. Comparison of propensity for carbon disclosure between developing and developed countries: A resource constraint perspective. Account. Res. J. 2013, 26, 6-34. [CrossRef]

17. Bhattacharyya, S.C. Energy sector management issues: An overview. Int. J. Energy Sect. Manag. 2007, 1, 13-33. [CrossRef]

18. Ji, J.; Zhang, Z.; Yang, L. Carbon emission reduction decisions in the retail-/dual-channel supply chain with consumers' preference. J. Clean. Prod. 2017, 141, 852-867. [CrossRef]

19. Aust, G. Vertical Cooperative Advertising and Pricing Decisions in a Manufacturer-Retailer Supply Chain: A Game-Theoretic Approach. In Vertical Cooperative Advertising in Supply Chain Management; Springer: New York, NY, USA, 2015.

20. Wang, C.L.; Wang, W.; Huang, R. Supply chain enterprise operations and government carbon tax decisions considering carbon emissions. J. Clean. Prod. 2017, 152, 271-280. [CrossRef] 
21. Chen, J.X.; Chen, J. Supply chain carbon foot printing and responsibility allocation under emission regulations. J. Environ. Manag. 2017, 188, 255-267. [CrossRef]

22. Xia, L.J.; Hao, W.Q.; Qin, J.J. Carbon emission reduction and promotion policies considering social preferences and consumers' low-carbon awareness in the cap-and-trade system. J. Clean. Prod. 2018, 195, 1105-1124. [CrossRef]

23. Tian, Y.; Govindan, K.; Zhu, Q. A system dynamics model based on evolutionary game theory for green supply chain management diffusion among Chinese manufacturers. J. Clean. Prod. 2014, 80, 96-105. [CrossRef]

24. Jingchao, Z.; Kotani, K.; Saijo, T. Low-quality or high-quality coal? Household energy choice in rural Beijing. Energy Econ. 2019, 78, 81-90. [CrossRef]

25. Nouira, I.; Hammami, R.; Frein, Y.; Temponi, C. Design of forward supply chains: Impact of a carbon emissions-sensitive demand. Int. J. Prod. Econ. 2016, 173, 80-98. [CrossRef]

26. Luo, R.L.; Fan, T.J.; XIA, H. The game analysis of carbon reduction technology investment on supply chain under carbon cap-and trade rules. Chin. J. Manag. Sci. 2014, 22, 44-53.

27. Knuth, S. "Breakthroughs" for a green economy? Financialization and clean energy transition. Energy Res. Soc. Sci. 2018, 41, 220-229. [CrossRef]

28. Aljazzar, S.M.; Gurtu, A.; Jaber, M.Y. Delays-in-payments-A strategy to reduce carbon emissions from supply chains. J. Clean. Prod. 2017, 170, 636-644. [CrossRef]

29. Peng, H.J.; Pang, T. Financing strategies for a capital-constrained supplier under yield uncertainty. Soc. Sci. Electron. Publ. 2016. [CrossRef]

30. Yang, L.; Zhang, Q.; Ji, J.N. Pricing and carbon emission reduction decisions in supply chains with vertical and horizontal cooperation. Int. J. Prod. Econ. 2017, 191, 286-297. [CrossRef]

31. Zhi, B.D.; Chen, J.L.; Liu, X.H. The Coordination Strategy for Two-tier Supply Chains with a Cost-sharing Contract in the Cap-and-Trade Mechanism. Chin. J. Manag. Sci. 2017, 25, 48-56.

32. Sun, M.J.; Peng, H.J.; Wang, S. Cost-Sharing Mechanisms for A Wood Forest Product Supply Chain under Carbon Cap-and-Trade. Sustainability 2018, 10, 43-45. [CrossRef]

33. Madani, S.R.; Rasti-Barzoki, M. Sustainable supply chain management with pricing, greening and governmental tariffs determining strategies: A game-theoretic approach. Comp. Ind. Eng. 2017, 105, 287-298. [CrossRef]

34. Fang, G.; Tian, L.; Fu, M.; Sun, M. The impacts of carbon tax on energy intensity and economic growth-A dynamic evolution analysis on the case of China. Appl. Energy 2013, 110, 17-28. [CrossRef]

35. Zhang, X.Y.; Han, Y.M.; Ge, W.; Yan, D.; Chen, Y. Design and Application of a Visual System for the Supply Chain of Thermal Coal Based on Big Data. Available online: https://www.researchgate.net/publication/325884115_Design_ and_Application_of_a_Visual_System_for_the_Supply_Chain_of_Thermal_Coal_Based_on_Big_Data (accessed on 25 May 2019).

36. Tseng, S.C.; Hung, S.W. A strategic decision-making model considering the social costs of carbon dioxide emissions for sustainable supply chain management. J. Environ. Manag. 2014, 133, 315-322. [CrossRef] [PubMed]

37. Peng, H.J.; Pang, T. A Mutual Subsidy Mechanism for a seasonal product supply chain channel under double price regulation. Asia-Pac. J. Oper. Res. 2018, 35, 1-26. [CrossRef]

38. Xu, X.; He, P.; Xu, H.; Zhang, Q. Supply chain coordination with green technology under cap-and-trade regulation. Int. J. Prod. Econ. 2017, 183, 433-442. [CrossRef]

39. Du, S.F.; Zhu, J.; Jiao, H.F.; Ye, W.Y. Game-theoretical analysis for supply chain with consumer preference to low carbon. Int. J. Prod. Res. 2015, 53, 3753-3768. [CrossRef]

(C) 2019 by the authors. Licensee MDPI, Basel, Switzerland. This article is an open access article distributed under the terms and conditions of the Creative Commons Attribution (CC BY) license (http://creativecommons.org/licenses/by/4.0/). 